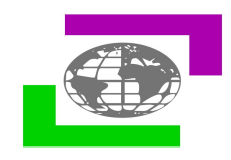

\title{
Solubility Enhancement of Antihyperlipidemic Drug by Solvent Diffusion Technique
}

\author{
Anjli Chauhan*, Gaurav Gupta, Pratyush Jain, Alok Pal Jain \\ RKDF College of Pharmacy, Bhopal (M.P.) India
}

Sarvepalli Radhakrishnan University Bhopal (M.P.) India

\begin{abstract}
Article Info: Received 19 July 2021; Accepted 20 September 2021
DOI: https://doi.org/10.32553/jbpr.v10i5.882

Corresponding author: Anjli Chauhan

Conflict of interest statement: No conflict of interest
\end{abstract}

\begin{abstract}
Poor aqueous solubility of drugs is major limiting factor with many new drugs in their successful launch in market in spite of their potential pharmacokinetic activity. Therefore, poor solubility is critical factor if the molecule is to survive the pharmaceutical development process. In the current work, it was planned to enhance the solubility of antihyperlipidemic drug by solvent diffusion technique. For this the drug clofibrate and excipients were procured and spherical agglomerates were prepared and evaluated. The findings of the study states the novelty the hypothesis.
\end{abstract}

Keywords: Solubility, Diffusion, Agglomerates

\section{Introduction}

Low aqueous solubility is the major problem encountered with formulation development of new chemical entities as well as generic development. Poor aqueous solubility of drugs is major limiting factor with many new drugs in their successful launch in market in spite of their potential pharmacokinetic activity. About $90 \%$ of all compounds in today's pharmaceutical drug delivery pipelines are reported to be poorly soluble in water. This process enormous problem for the industry for an active pharmaceutical ingredient cannot reach its molecular target in the body if the drug remains undissolved in the gastrointestinal tract (GIT) and is eventually excreted. Therefore, poor solubility is critical factor if the molecule is to survive the pharmaceutical development process. Even those molecules that would have highly beneficial effect on their physiological target would not be further developed if their bioavailability is limited by their solubility in water. Further poorly water-soluble drugs are generally administered at much higher dose than the actual dose in order to achieve necessary drug plasma level leading to improved adverse reaction and cost of therapy and often yields erratic pharmacological response and hence poor patient complains. In addition, the manufacturing cost would increase since a large amount of active pharmaceutical ingredient (API) might be consumed to develop and manufacture the drug product. [1]

Hyperlipidemia is a condition characterized by an elevation of any or all lipid profile and/or lipoproteins in the blood. Although elevated low density lipoprotein cholesterol (LDL) is thought to be the best indicator of atherosclerosis risk, 
dyslipidemia can also describe elevated total cholesterol (TC) or triglycerides (TG), or low levels of high-density lipoprotein cholesterol (HDL). Hyperlipidemia is the major precursor of lipid related ailment such as atherosclerosis, coronary artery disease and also involved in sudden death syndrome. The main cause of hyperlipidemia includes changes in lifestyle habits in which risk factor is mainly poor diet. Although these techniques have commonly been used to increase dissolution rate of the drug, there are practical limitations with these techniques, the desired bioavailability enhancement may not always be achieved. [2] In the current work, it was concentrated on improvement of the solubility of clofibrate drug by solvent diffusion technique.

\section{Experimental work}

\section{Identification and collection of all proposed drug material}

The drug clofibrate and other required excipients were collected from Rouzel Pharma, Chandigarh as gift sample. All the collected material was used in the for the proposed work.

\begin{tabular}{|c|c|}
\hline $\begin{array}{l}\text { Preparation } \\
\text { agglomerates } \\
\text { technique }\end{array}$ & $\begin{array}{cr}\text { of } & \text { clofibrate } \\
\text { using } & \text { solvent }\end{array}$ \\
\hline
\end{tabular}

Three dissimilar organic solvents as good solvent including methyl acetate (MA), ethyl acetate (EA) and isopropyl acetate (IPA) were employed as a dispersed phase for making oilin-water emulsions $(\mathrm{O} / \mathrm{W})$. Crystallization was carried out in a cylindrical vessel equipped with three baffles. Clofibrate was dissolved in $15 \mathrm{ml}$ of good solvent. The solvent solutions were then poured dropwise during $3 \mathrm{~min}$, under stirring (500 rpm), into $485 \mathrm{ml}$ of water containing $0.1 \%$ w/v emulsifier. Tween 80 , SLS, PVP or HPMC were used as emulsifiers. After 15 min agitation by a propeller type stirrer, the agglomerates were separated from the solution by filtration under vacuum and then were placed in a thin layer in an oven at $60^{\circ} \mathrm{C}$ for $3 \mathrm{~h}$. The solubility of organic solvents in water was the basis of the selection of the solvents in making solvent-in-water emulsion. [3]

Table 1 Formula for Clofibrate spherical agglomerates

\begin{tabular}{|l|l|l|l|l|l|l|l|l|}
\hline $\begin{array}{l}\text { Formulation } \\
\text { Code }\end{array}$ & $\begin{array}{l}\text { Clofibrate } \\
(\mathrm{mg})\end{array}$ & $\begin{array}{l}\text { SLS } \\
(\mathbf{\%})\end{array}$ & $\begin{array}{l}\text { PVP } \\
(\%)\end{array}$ & $\begin{array}{l}\text { Tween } \\
80(\%)\end{array}$ & $\begin{array}{l}\text { HPMC } \\
(\%)\end{array}$ & $\begin{array}{l}\text { Methyl } \\
\text { acetate } \\
(\mathrm{ml})\end{array}$ & $\begin{array}{l}\text { Ethyl } \\
\text { acetate } \\
(\mathrm{ml})\end{array}$ & $\begin{array}{l}\text { Isopropyl } \\
\text { acetate } \\
(\mathrm{ml})\end{array}$ \\
\hline CLF F1 & 500 & 0.0130 & 00 & 00 & 00 & 20 & 60 & 20 \\
\hline CLF F2 & 500 & 0.0300 & 00 & 00 & 00 & 20 & 60 & 20 \\
\hline CLF F3 & 500 & 00 & 0.0125 & 00 & 00 & 20 & 60 & 20 \\
\hline CLF F4 & 500 & 00 & 0.0200 & 00 & 00 & 20 & 60 & 20 \\
\hline CLF F5 & 500 & 00 & 00 & 0.0350 & 00 & 20 & 60 & 20 \\
\hline CLF F6 & 500 & 00 & 00 & 0.0150 & 00 & 20 & 60 & 20 \\
\hline
\end{tabular}

\section{Evaluation of Clofibrate spherical agglomerates} Flow Properties

Pure Clofibrate and prepared spherical agglomerates were evaluated for bulk density and tapped density using density apparatus (TDA2, Campbell Electronics). The Carr's index and Hausners's ratio were then calculated by using $\rho b$ and $\rho t$. The angle of repose was determined by fixed funnel method. [4]

\section{Solubility Studies}

The solubility of prepared spherical agglomerates was investigated, by adding the excess drug particles in the solvents and shaking the glass vials for specific time until reaching equilibrium conditions. A $0.45 \mu$-membrane filter solution was used to filter the solutions. UV-Spectrophotometer was used to determine the absorbance of the filtrate solutions after suitable dilution. The experiments were 
undertaken at $25 \pm 0.1^{\circ} \mathrm{C}$. The mean of three determinations was used to calculate the solubility of the drug in the solvents. [5]

\section{Stability Studies}

The selected formulation was evaluated for its stability at $40 \pm 2^{\circ} \mathrm{C} / 75 \pm 5 \% \mathrm{RH}$ for about 2 months as per ICH guidelines. The samples were taken out after 3 months and evaluated for the drug content, solubility and in vitro release study. [6]

\section{Results and Discussion}

Flow Properties

These results confirm that spherical agglomeration drastically improved the flow and compaction behaviour of Clofibrate. All the findings were recorded in table 5.7

Table 2 Flow Properties of Clofibrate and prepared agglomerates

\begin{tabular}{|l|l|l|l|}
\hline Formulation Code & Angle of repose & Hausner's ratio & Carr's index \\
\hline Clofibrate & $22.10^{0}$ & 1.20 & $21.22 \%$ \\
\hline CLF F1 & $24.60^{0}$ & 1.20 & 8.20 \\
\hline CLFF2 & $20.10^{0}$ & 1.10 & 6.10 \\
\hline CLFF3 & $23.35^{0}$ & 1.30 & 6.75 \\
\hline CLF F4 & $20.15^{0}$ & 1.05 & 7.50 \\
\hline CLF F5 & $22.10^{0}$ & 1.50 & 7.15 \\
\hline CLF F6 & $25.20^{0}$ & 1.80 & 7.10 \\
\hline
\end{tabular}

\section{Solubility Studies}

The mean of three determinations was used to calculate the solubility of the drug in the solvents. The obtained results were recorded in table 5.9.

Table 3 Solubility studies of Clofibrate and prepared agglomerates

\begin{tabular}{|l|l|}
\hline Formulation Code & Solubility $(\boldsymbol{\mu g} / \mathbf{m l})$ in 0.1N HCl \\
\hline Clofibrate & $1113.10 \pm 50.10$ \\
\hline CLF F1 & $2220.20 \pm 40.25$ \\
\hline CLFF2 & $3265.50 \pm 20.20$ \\
\hline CLFF3 & $3345.30 \pm 10.30$ \\
\hline CLF F4 & $4212.15 \pm 10.30$ \\
\hline CLF F5 & $4345.30 \pm 20.10$ \\
\hline CLF F6 & $4480.10 \pm 20.20$ \\
\hline
\end{tabular}

\section{Stability Studies}

After 2 months of storage at accelerated storage condition, the prepared agglomerates formulation (CLF F2) doesn't show any significant different in results of drug content, solubility and in vitro release pattern, compared with zero time. This indicates the finalized formulation was quite stable.

\section{Conclusion}

The solvent diffusion technique (SDT) has changed into an operative technique to manufacture agglomerates of API crystals. Although, the planned technique showed benefits, such as cost effectiveness, that is considerably sensitive to the optimal of a stabilizer, which agonizes from an absence of systemic understanding in this field. In the existing study, the combination of different 
solvents and stabilizers were equated to examine any connections between the solvents and stabilizers.

\section{References}

1. Rong L. Water insoluble drug-formulation. $2^{\text {nd }}$ edition. New York: CRC Press. 2008; 14.

2. Daravath Bhaskar, Chella Naveen, Vemula Sateesh Kumar, Tadikonda Rama Rao. Solubility and dissolution enhancement of flurbiprofen by solid dispersion using hydrophilic carriers. Brazilian Journal of Pharmaceutical Sciences. 2017;53(4):1-10.

3. Bhusnure G Omprakash, Yogita Mohite, Gholve S Sachin, Sidram P Giram, Thonte SS. Formulation and evaluation of poorly aqueous soluble drug by solid dispersion method. Journal of Pharmacy Research. 2016; 10 (1): 33-40.

4. Baxter T, Barum R, Prescott JK. General principles of bulk solids handling. In: Augsburger LL and Stephen WH. Pharmaceutical dosage forms: Tablets. Unit Operations and Mechanical Properties. Newyork: Informa Healthcare. 2003; $3^{\text {rd }}$ edition, 75-110.

5. Leuner C, Dressman J. Improving drug solubility for oral delivery using solid dispersions. European Journal of Pharmacy Biopharmaceutics. 2000; 50:47-60.

6. Guideline ICH. Stability testing of new drug substances and products. Q1A (R2), current step. 2003. 